\title{
Sperm Parameters: Paradigmatic Index of Good Health and Longevity
}

\author{
Alexander E. Omu \\ Department of Obstetrics and Gynaecology, Faculty of Medicine, Health Sciences Centre, Kuwait University, Kuwait
}

\section{Key Words}

Spermatozoa parameters - Longevity - Oxidative stress . Low testosterone

\begin{abstract}
Since the discovery of spermatozoon by Anton van Leeuwenhoek in 1677, there has been an ever increasing understanding of its role in reproduction. Many factors adversely affect sperm quality, including varicocele, accessory gland infection, immunological factors, congenital abnormalities, and iatrogenic systemic and endocrine causes, such as diabetes mellitus, obesity, metabolic syndrome, and smoking. The mechanisms responsible for the association between poor sperm parameters and ill health may include oxidative stress, low-grade inflammation, low testosterone, and low sex-hormone-binding globulin. Oxidative stress in the testicular microenvironment may result in decreased spermatogenesis and sperm DNA damage, loss of sperm motility, and abnormal sperm morphology. Low testosterone caused by advanced age, visceral obesity, and inflammation is associated with the development of cardiovascular disease. Hence, semen analysis has an important role in the routine evaluation of idiopathic male infertility, usually manifested as low sperm counts, impaired sperm motility, or absence of sperm, and remains the most common single diagnostic tool. Several studies have shown an inverse relationship between semen quality and medical disorders. This review elu-
\end{abstract}

cidates the effect of medical disorders and social habits on sperm quality, the mechanisms that are involved in the impairment of sperm quality, and whether or not sperm quality can be used as an index of good health and longevity in a man.

(c) 2013 S. Karger AG, Basel

\section{Introduction}

In 1677, Antonie van Leeuwenhoek discovered spermatozoa in a semen sample using a single-lens microscope that could magnify objects up to $\times 200[1,2]$, far more powerful than the magnification of $\times 20-30$ of compound microscopes of the late 14 th century. With the aid of this microscope, he discovered 'animalcules', small motile elements in semen, which aid fertilization. The major breakthrough, however, came in 1875, when Oscar Hertig, using sea urchins, demonstrated that the sperm head actually fused with the female germ cells to form the nucleus of a new being [3]. From 1920 to 1950, John Macleod [4], working in New York, USA, made two important observations: that semen analysis can be used as an index of human fertility through sperm concentration, motility, and morphology, and that oxygen metabolism has a role in causing altered sperm quality. The World Health Organization (WHO) standardized the procedures for semen analysis by producing a guidance manu-

\begin{tabular}{ll}
\hline KARGER & $\begin{array}{l}\text { () 2013 S. Karger AG, Basel } \\
1011-7571 / 13 / 0227-0030 \$ 38.00 / 0 \quad \text { Karger }\end{array}$ \\
$\begin{array}{l}\text { E-Mail karger@karger.com } \\
\text { www.karger.com/mpp }\end{array}$ & $\begin{array}{l}\text { This is an Open Access article licensed under the terms of the } \\
\text { Creative Commons Attribution-NonCommercial 3.0 Un- } \\
\text { ported license (CC BY-NC) (www.karger.com/OA-license), } \\
\text { applicable to the online version of the article only. Distribu- } \\
\text { tion permitted for non-commercial purposes only. }\end{array}$
\end{tabular}

Prof. Dr. Alexander E. Omu, FRCOG

Department of Obstetrics and Gynecology, Faculty of Medicine Health Sciences Centre, Kuwait University

PO Box 24923, Safat 13110 (Kuwait)

E-Mail Omu@hsc.edu.kw 
al for semen analysis, which is updated every 10 years [5]. These sperm parameters are now used to identify males with subfertility and sterility [6].

Spermatogenesis is a process that lasts for about 70 days of transformation from spermatogonia through primary spermatocytes, secondary spermatocytes, and spermatids to spermatozoa, which mature in the epididymis $[7,8]$. There are large terminal deletions of the long arm of the $\mathrm{Y}$ chromosome $(\mathrm{Yq})$ in men with azoospermia, suggesting that azoospermia factors essential for spermatogenesis reside within the euchromatic region of Yq $[9,10]$. Spermatogenesis is regulated by testosterone and follicle-stimulating hormone (FSH), released by the pituitary gland. The FSH stimulates primary spermatocytes to undergo the first meiotic division. Testosterone, secreted and released by the Leydig cells of the testes under the control of luteinizing hormone, stimulates the development of secondary spermatocytes into mature spermatozoa [11]. The production, maturation, and longevity of spermatozoa are affected early in the pathogenesis of many medical conditions. Reports suggest that sperm parameters can indicate the health status of a man $[12,13]$.

Health, defined in its broader sense, is 'a state of complete physical, mental and social well-being and not merely the absence of disease or infirmity' $[14,15]$. Prolonged psychological stress is a factor in cognitive impairment with aging, depressive illness, and expression of disease [16]. Apart from accident, homicide, and suicide, the main causes of death worldwide include cancer, cardiovascular disorders, diabetes mellitus, infection, and hypertension [17].

\section{Biomarkers for Monitoring Health}

A biomarker, or biological marker, is in general a substance used as an indicator of a biological state. It is a characteristic that is objectively measured and evaluated as an indicator of normal biological processes, pathogenic processes, or pharmacologic responses to a therapeutic intervention $[18,19]$. Biomarkers can therefore be substances in the body that may indicate risk or the presence of disease [20,21]. In a comparative study of couples attending a combined infertility clinic, malondialdehyde, a marker of oxidative stress, was strongly associated with obesity and poor semen parameters [22]. Various biomarkers have been used in the diagnosis, monitoring, and treatment of medical disorders, in the blood, urine, and other body fluids. A widely used biomarker for diagnosis and assessment of anemia is the level of hemoglobin. Sim-

Sperm Parameters Are an Index of Good Health and Longevity ilarly, kidney function is assessed with the level of creatinine in the blood, on its own or as the glomerular filtration rate, and with blood urea nitrogen [23]. Diabetes mellitus is marked by a high fasting glucose level in the blood [24]. Several tumor markers have been associated with several types of cancers, including breast, colon, liver, ovarian, prostate, testicular, and pancreatic cancers [25-28]. The seminal concentration, motility, and morphology of spermatozoa have been used as biomarkers of male fertility potential since the middle of the 20th century [4]. With the recent advances in sperm proteins, proteomic techniques will have an important role in the diagnosis of sperm dysfunction [29].

\section{Relevance of Semen Analysis}

Semen analysis has an important role in the routine evaluation of idiopathic male infertility as a result of ductal obstruction from congenital abnormal development or infection, or testicular damage. According to the WHO, a normal sperm count is a concentration of 15 million spermatozoa $/ \mathrm{ml}$, with a total semen volume of at least $2 \mathrm{ml}$. The total number of spermatozoa in the ejaculate should be at least 40 million: $75 \%$ viable, $30 \%$ of normal shape and form, 50\% swimming forward however sluggishly, and $25 \%$ swimming with a rapid forward movement [5]. Common causes of abnormal sperm parameters are varicocele, accessory gland infection, immunological factors, congenital abnormalities, obstructive azoospermia, and iatrogenic, systemic, and endocrine disorders [30]. The most common manifestation of male infertility is a low sperm count [31].

\section{Limitations of Semen Analysis and Advances in Sperm Testing}

Semen analysis deals with numbers and averages. Furthermore, having a sperm count below 15 million spermatozoa/ml $[5,6]$ does not indicate that a man will be unable to father a child; likewise, having a higher sperm count does not guarantee that a man will be able to do so. Moreover, there are no reliable tests of sperm function. Investigations for a more precise cause of infertility have continued in the modern era of assisted reproductive technology. One such investigation is sperm proteomics, which is the identification and functional study of sperm proteins with mass spectrometry [32-34]. In a recent study, Lazaros et al. [35] examined the prognostic value 
Table 1. Sociodemographic and clinical characteristics of the patients

\begin{tabular}{|c|c|c|}
\hline Characteristics & $\mathrm{n}$ & $\%$ \\
\hline Mean age $( \pm S D)$, years & $34.6 \pm 8.4$ & \\
\hline$\leq 20$ & 24 & 1.1 \\
\hline $21-30$ & 673 & 29.9 \\
\hline $31-40$ & 1,039 & 46.2 \\
\hline $41-50$ & 359 & 15.9 \\
\hline $51-60$ & 105 & 4.7 \\
\hline$<60$ & 51 & 2.3 \\
\hline Mean duration of infertility $( \pm S D)$, years & $7.4 \pm 4.8$ & \\
\hline Primary infertility & 1,526 & 67.8 \\
\hline Secondary infertility & 725 & 32.2 \\
\hline Second marriage & 545 & 24.2 \\
\hline Mean BMI $( \pm$ SD $)$ & $28.4 \pm 3.8$ & \\
\hline Underweight (BMI <18.5) & 54 & 2.4 \\
\hline Normal weight (BMI 18.5-25) & 688 & 30.6 \\
\hline Overweight (BMI 25-29.9) & 626 & 27.8 \\
\hline Obesity 1 (BMI 30-34.9) & 599 & 26.6 \\
\hline Obesity $2(35-39.9)$ & 221 & 9.8 \\
\hline Obesity 3 (morbid, BMI $\geq 40$ ) & 63 & 2.8 \\
\hline \multicolumn{3}{|l|}{ Sperm parameters } \\
\hline Polyzoospermia & 48 & 2.1 \\
\hline Normozoospermia & 1,094 & 48.6 \\
\hline Oligozoospermia & 925 & 41.1 \\
\hline Azoospermia & 184 & 8.2 \\
\hline Asthenozoospermia & 368 & 20.9 \\
\hline Teratozoospermia & 346 & 15.4 \\
\hline Leukocytospermia & 688 & 30.6 \\
\hline \multicolumn{3}{|l|}{ Genital disorders } \\
\hline Genital injuries & 234 & 10.4 \\
\hline Hernia/herniorrhaphy & 87 & 3.9 \\
\hline Hydrocelectomy & 21 & 0.9 \\
\hline Varicocele/vasectomy & 86 & 3.8 \\
\hline Cryptorchidism/orchidopexy & 24 & 1.1 \\
\hline Testicular sports injury & 16 & 0.7 \\
\hline \multicolumn{3}{|l|}{ Chromosomal } \\
\hline Klinefelter syndrome & 5 & 0.22 \\
\hline Cystic fibrosis/CFTR & 3 & 0.13 \\
\hline Y microdeletion & 2 & 0.09 \\
\hline XX male & 1 & 0.04 \\
\hline \multicolumn{3}{|l|}{ Endocrine } \\
\hline Hypogonadotropic/hypogonadism & 3 & 0.13 \\
\hline Hyperprolactinemia & 18 & 0.80 \\
\hline Infection & 134 & 6.0 \\
\hline Sexually transmitted & 38 & 1.70 \\
\hline Mumps & 22 & 1.00 \\
\hline Other & 74 & 3.30 \\
\hline Malignancies & 25 & 1.1 \\
\hline
\end{tabular}

of semen flow cytometry on the successful outcome of intrauterine insemination (IUI). The authors concluded that semen flow cytometry could be used to evaluate semen samples before IUI and potentially prognosticate the outcome. Sperm DNA fragmentation and Y-chromosome microdeletion are common among patients with oligozoospermia and have a major effect on the management of obstetric and neonatal outcomes. Hence, monitoring with sperm chromatin structural assay (SCSA) for sperm DNA fragmentation has been increasingly used to improve treatment outcomes [36] and guide couples to make informed reproductive decisions, including the decision to seek donor insemination [37] or adoption.

\section{Decline in Sperm Quality}

In 1992, in a publication that generated tremendous controversy, Carlsen et al. [38] drew attention to a 50year decline in sperm parameters from 1938 to 1990 that appeared to have been supported by two other subsequent publications $[39,40]$. The biological significance of these changes is emphasized by a concomitant increase in the incidence of genitourinary abnormalities such as testicular cancer, cryptorchidism, and hypospadias, suggesting a growing impact of factors with serious effects on male gonadal function [41]. Consequently, a search for attributable factors such as the environment, endocrine disruption, estrogens, and phthalates [42] became an urgent necessity. In addition to these factors, behavioral changes such as smoking and sexually transmitted diseases may have intrauterine effects on the growing fetus that may manifest as chronic medical conditions in adult life $[43,44]$. In a recent study [45], male rats exposed in utero to certain phthalate esters administered to their mothers exhibited a high frequency of cryptorchidism, hypospadias, and abnormal testes associated with suppression of testosterone levels in the fetal testis, which may also impair sperm production and motility.

\section{Sperm Parameters and Health Disorders}

During a 16-year period from January 1, 1995, to December 31,2011, semen analysis was carried out according to WHO guidelines [5] on 2,251 men who presented with inability to achieve conception despite cohabitation with their spouses without the use of contraception for more than 12 months. The sociodemographic and clinical characteristics of the patients are shown in table 1 . The 
Table 2. Effects of medical disorders on sperm parameters

\begin{tabular}{|c|c|c|c|c|c|c|c|c|c|}
\hline & \multirow{2}{*}{$\begin{array}{l}\text { Total number } \\
(\%)\end{array}$} & \multirow{2}{*}{$\begin{array}{l}\text { Azoo- } \\
\text { spermia } \\
(\mathrm{n}=184)\end{array}$} & \multirow{2}{*}{$\begin{array}{l}\text { OligoZP } \\
(\mathrm{n}=925)\end{array}$} & \multirow{2}{*}{$\begin{array}{l}\text { NormoZP } \\
(\mathrm{n}=1,094)\end{array}$} & \multirow{2}{*}{$\begin{array}{l}\text { AsthZP } \\
(\mathrm{n}=1,121)\end{array}$} & \multirow{2}{*}{$\begin{array}{l}\text { Norm. Mot. } \\
(\mathrm{n}=1,130)\end{array}$} & \multicolumn{2}{|c|}{ Sperm morphology } & \multirow{2}{*}{$\begin{array}{l}\text { Leuko- } \\
\text { cyto- } \\
\text { spermia } \\
(\mathrm{n}=688)\end{array}$} \\
\hline & & & & & & & $<30 \%$ & $\geq 30 \%$ & \\
\hline Smoking & $810(36)$ & $68(37)$ & $538(58.2)$ & $204(18.7)$ & $601(53.6)$ & $209(18.5)$ & $371(43.8)$ & $439(31.3)$ & $313(45.5)$ \\
\hline Diabetes mellitus & $189(8.4)$ & $21(11.4)$ & $120(12.9)$ & $48(4.4)$ & $125(11.2)$ & $70(6.2)$ & $79(9.3)$ & $120(8.6)$ & $98(14.2)$ \\
\hline Hypertension & $212(9.4)$ & $34(18.5)$ & $78(8.4)$ & $104(9.1)$ & $84(7.5)$ & $94(8.3)$ & $75(8.9)$ & $103(7.4)$ & $82(11.9)$ \\
\hline Metabolic syndrome & $146(6.2)$ & $12(6.5)$ & $83(9.0)$ & $45(4.1)$ & $86(7.7)$ & $42(3.7)$ & $58(6.9)$ & $70(5.0)$ & $68(9.9)$ \\
\hline Herniorrhaphy & 87 (3.9) & $52(28.3)$ & $31(3.4)$ & $4(0.3)$ & $29(2.6)$ & $6(0.5)$ & $28(3.3)$ & $7(0.5)$ & $35(5.1)$ \\
\hline \multicolumn{10}{|l|}{ Obesity } \\
\hline $\mathrm{BMI} \geq 30$ & $890(39.5)$ & $100(54.4)$ & $498(53.8)$ & $272(24.9)$ & $586(52.2)$ & $314(27.8)$ & $365(43.1)$ & $375(26.7)$ & $101(14.7)$ \\
\hline Varicocele & $86(3.9)$ & $14(7.6)$ & $50(5.4)$ & $22(2.0)$ & $57(5.1)$ & $15(1.3)$ & $28(3.3)$ & $44(3.1)$ & $32(4.7)$ \\
\hline \multicolumn{10}{|l|}{ Malignancies } \\
\hline Seminoma, leukemia & $25(1.1)$ & $3(1.6)$ & $15(1.6)$ & $7(0.6)$ & $18(1.6)$ & $4(0.35)$ & $9(1.1)$ & $13(0.9)$ & $8(1.2)$ \\
\hline Genital infection & $134(6.0)$ & $15(8.1)$ & $86(9.3)$ & $33(3.0)$ & $88(7.9)$ & $31(2.7)$ & $75(8.9)$ & $44(3.1)$ & $82(11.9)$ \\
\hline Appendidectomy & $16(0.7)$ & $2(1.1)$ & $6(0.6)$ & $8(0.7)$ & $9(0.8)$ & $5(0.4)$ & $5(0.6)$ & $9(0.6)$ & $5(0.7)$ \\
\hline Others & $34(1.5)$ & $8(5.7)$ & $16(1.7)$ & $12(1.1)$ & $15(1.3)$ & $13(1.2)$ & $9(1.1)$ & $19(1.4)$ & $11(1.6)$ \\
\hline
\end{tabular}

Values are presented as numbers (\%). Smoking, diabetes mellitus, metabolic syndrome, obesity, and genital infection are more common with oligozoospermia, asthenozoospermia, and teratozoospermia ( $p<0.05$ to 0.001 ). Herniorrhaphy, hypertension, and obesity are associated with azoospermia ( $<<0.05$ to 0.01$)$. OligoZP = Oligozoospermia; NormoZP = normozoospermia; AsthZP = asthenozoospermia; Norm. Mot. $=$ normal motility.

mean age was $34 \pm 8$ years (range 18-78) and $156(7 \%)$ of the men were above 50 years of age. Primary infertility was more common than secondary infertility, i.e. $\mathrm{n}=$ $1,526(67.8 \%)$ versus $n=750(32.2 \%)(\mathrm{p}<0.05)$. Using the body mass index (BMI), 54 (2.4\%) were determined to be underweight and $883(39.5 \%)$ were obese, with $63(2.8 \%)$ being grossly obese [46]. Polyzoospermia, defined as a sperm concentration of more than $250 \mathrm{million} / \mathrm{ml}$, occurred in $48(2.1 \%)$ of the men, whereas azoospermia occurred in $184(8.2 \%)$. About $234(10.1 \%)$ of the men had had some form of genital operation, and cryptorchidism occurred in $24(1.1 \%)$, while $134(6.0 \%)$ had genital infection. The effects of chronic medical disorders and social habits on semen quality are summarized in table 2 . Health disorders among the men included diabetes mellitus, obesity, hypertension, and genital operations such as herniorrhaphy and orchidopexy. Abnormalities such as azoospermia, oligozoospermia, asthenozoospermia, teratozoospermia, and leukocytospermia were more common with these disorders by 1.5 - to 3.5 -fold. Similarly, FSH increased in an inverse relation with testicular volume, determined by comparative bead orchidometry ( $\mathrm{r}=$ -0.634 ), and low testosterone was strongly associated with genital operations [46]. Medical disorders and social habits had differential effects on sperm parameters as discussed below.

Sperm Parameters Are an Index of Good Health and Longevity

\section{Effect of Obesity on Sperm Parameters}

The relationship between increased BMI and sperm parameters has been evaluated in several studies [47-58]. All of these studies that collectively evaluated over 125,000 men with infertility showed that an increased BMI was associated with reduced testicular volume, a low sperm count, impaired sperm motility, increased sperm DNA fragmentation, increased infertility, a low serum testosterone level, reduced libido, and erectile dysfunction. Obesity is now an epidemic in both men and women worldwide, resulting in compromised physical and psychological well-being [48]. Much is known about the negative impact of obesity on pubertal sexual maturation resulting in hypogonadism [50]. Obesity is also a risk factor for stress urinary incontinence [51] and type 2 diabetes mellitus and the hormone profile is described as hyperestrogenic hypogonadotropic hypogonadism due to overactivity of aromatase [48]. Underweight or overweight may lead to a low sperm count and infertility [47, 52-54], and overweight men generally have less sex than do nonoverweight men [55-57]. A National Institute of Environmental Health Sciences (NIEHS) study showed that a 3-point increase in BMI increased the risk of infertility by $10 \%$ in men [47].

There are several ways that obesity may impair fertility in men. Obesity is associated with a change in hor- 
Fig. 1. Effects of diabetes mellitus on sperm quality. a Transmission electron microscopy of a nondiabetic patient with a normal sperm head $(\mathrm{NH})$ mid-piece with abundant mitochondria and a normal tail (NT) and a normal cross section with 9-2n fibrils. b Sperm of ejaculated semen of an insulin-dependent diabetic man with infertility showing a globular head (GH), a cytoplasmic mid-piece with scanty mitochondria, elongated spermatide (ESp) and round spermatids (RSp), and a secondary spermatocyte and apoptotic body (Ap).
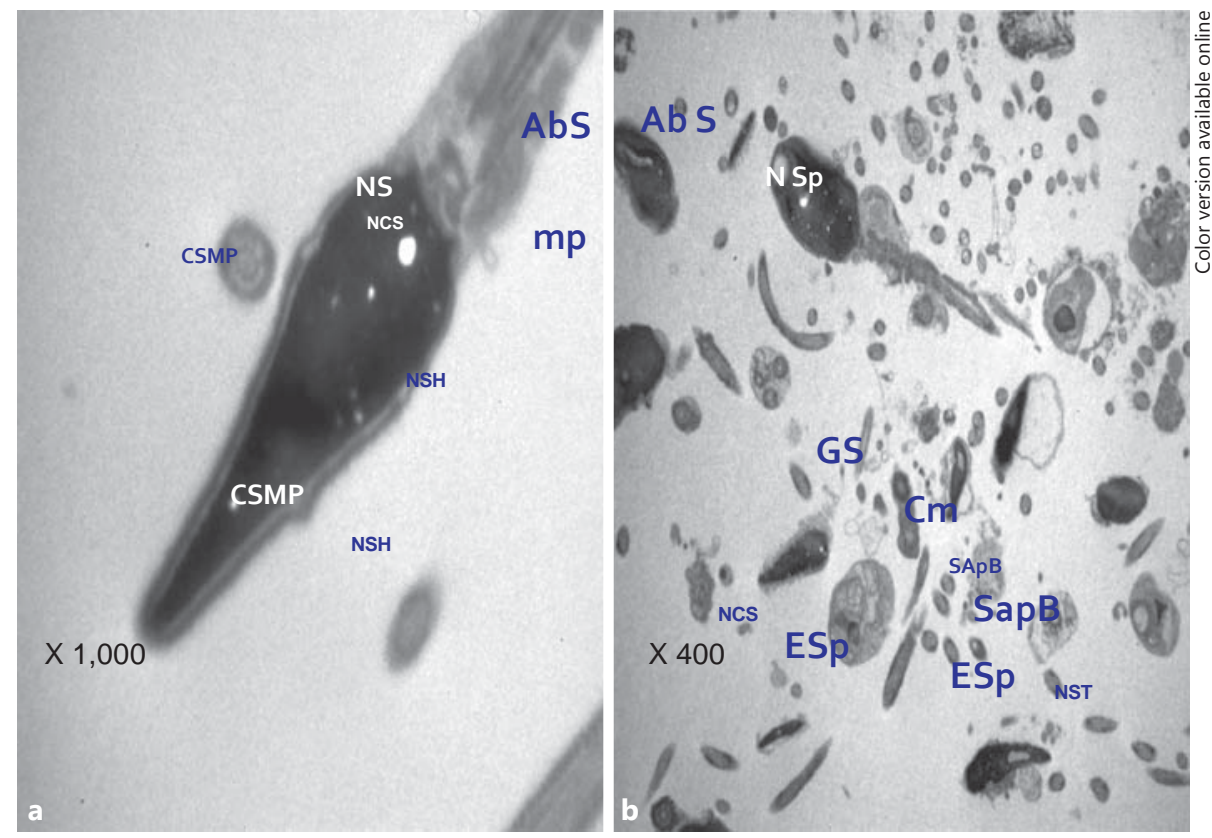

monal environment characterized by elevated estrogen and reduced testosterone levels. As sperm production is highly dependent on testosterone, low levels of this hormone are likely to impair sperm production [51, 58]. Obesity gives rise to sleep apnea, insulin resistance, and cardiovascular disorders which give rise to erectile dysfunction and collectively result in hypoandrogenism and impaired spermatogenesis. A recent study by Bakos et al. [59] using mice showed that both sperm parameters and embryonic development were significantly reduced when the male partner was obese. Obesity induces adipose cell enlargement and the adipose secretion of adipokines such as interleukin (IL)-1 $\beta$, IL-6, IL-8, C-reactive protein (C$\mathrm{RP}$ ), and tumor necrosis factor (TNF)- $\alpha$. In addition, obesity is associated with overactivity of aromatase that results in hyperestrogenism and consequent suppression of the hypothalamic-pituitary-gonodal axis. This causes hypoandrogenism and subsequent impaired spermatogenesis [59].

\section{Diabetes Mellitus}

In a case-control study of 31 diabetic men with infertility [60], the mean glycosylated hemoglobin (HbA1c) value in diabetic patients was $8.8 \pm 4.1 \%$ compared to $4.6 \%$ in the nondiabetic controls $(\mathrm{p}<0.05)$. Poor diabetic con- trol (HbA1c $\geq 7 \%$ ) was significantly associated with impaired sperm motility (reduced progressive motility and asthenozoospermia) and sperm defects (abnormal morphology such as double head, round and elongated spermatids and cytoplasmic mid- and tail pieces) $(\mathrm{p}<0.05)$ as shown in figure 1. Similarly, poor diabetic control was associated with an abnormal lipid profile: high cholesterol, triglycerides, LDL, and VLDL and lower HDL. Leukocytospermia was also more common in diabetic men with poor diabetic control. There were positive correlations between serum glucose level and $\mathrm{HbAlc}$, and the sperm DNA fragmentation index (DFI), and an inverse relationship with butyrylcholinesterase (BuChE) and total antioxidant capacity [60]. In a similar study of 27 diabetic men with infertility, Agbaje et al. [61] found that diabetes was associated with increased nuclear and mitochondrial DNA (mtDNA) sperm damage.

\section{Metabolic Syndrome}

Metabolic syndrome is a complex disorder consisting of multiple interrelated factors including insulin resistance, central adiposity, dyslipidemia, endothelial dysfunction, atherosclerotic disease, and low-grade inflammation. Obesity is associated with the development of metabolic syndrome, which has its own plethora of del- 
eterious effects on the sperm [62-64]. Metabolic syndrome plays a central role in obesity in the development of a chronic low-grade inflammatory state that leads to insulin resistance and endothelial and microvascular dysfunction. The subsequent increase in cytokine production recruits immune cells in the extracellular environment, inducing an overall systemic inflammation, which is the link between obesity and metabolic syndrome [65]. Similarly, it is associated with biomarkers such as C-RP, IL-6, and TNF- $\alpha$ that give rise to insulin resistance. Ultimately, this may lead to a low sperm count, impaired motility, and abnormality of sperm morphology [66-68]. On the other hand, metabolic syndrome poses a threat for the development of coronary heart disease and adiposity [69]. A recent study showed that IL-8 was significantly elevated in heart failure patients with metabolic syndrome compared to controls [70]. High IL-8 levels have also been noted in patients with T2DM with a direct correlation with hemoglobin A1C levels.

\section{Effects of Hypertension on Sperm Parameters}

Few studies have evaluated the effects of the treatment of hypertension with calcium ion channel blockers [71] and hypertension itself [72] on sperm parameters. It is known that hypertension can cause problems with erection, either directly or as a side effect of medication. Calcium channel blockers like nifedipine have a direct adverse effect on spermatogenesis, motility, and sperm longevity [73]. Muciaccia et al. [72], in a recent evaluation of 25 hypertensive men and 25 normotensive controls, showed high levels of clusterin, a biomarker of hypertension. The sperm DFI was higher in hypertensive men than in controls, with a significant correlation between high levels of clusterin immunolabeling and the presence of sperm DNA damage. They also reported reduced forward sperm motility and lower sperm vitality in the hypertensive men.

\section{Seminal Infection}

In a comparative study of 50 men with seminal infection, those with infection had a 3 -fold lower sperm count than those without [74]. Chlamydia trachomatis infection was associated with poor semen quality in young men with prostatitis [75-77] and a high prevalence of $C$. trachomatis in males was associated with a low sperm count in Kuwait [76, 77] and Nigeria [78]. A recent study

Sperm Parameters Are an Index of Good Health and Longevity assessed the effect of human immunodeficiency virus (HIV) and hepatitis C (HCV) and B (HBV) virus infection on semen parameters from $27 \mathrm{HCV}, 34 \mathrm{HIV}, 30$ $\mathrm{HBV}$, and $41 \mathrm{HCV}$-HIV-seropositive patients and compared with those of a control population of healthy seronegative subjects. Tests for detection of HIV, HCV, and HBV were performed on seminal samples. The sperm concentration, mean sperm motility, and sperm viability were significantly decreased in $\mathrm{HCV}$ - and HBV- and HCV-HIV-seropositive males compared to controls $(\mathrm{p}<$ $0.001)$ [79].

\section{Smoking and Sperm Parameters}

Studies evaluating the effect of smoking on sperm parameters have produced controversial results [80-82]. Marinelli et al. [80] reported that smoking has a limited effect on sperm parameters. However, other studies have shown a strong association between smoking and reduced semen quality $[81,82]$. In a study of heavy smokers, a zincdeficient diet was associated with high cadmium testicular accumulation, comparable to diets supplemented with cadmium. The serum concentration of cadmium had a linear correlation with TNF- $\alpha$ and IFN- $\gamma$, but not with IL-4 [83], with consequent poor sperm parameters [84]. Fawzy et al. [85] reported that both sheesha and cigarette smoking adversely affected semen quality. Sheesha smoking was more significantly associated with a decrease in sperm with a normal morphology and lower testosterone levels relative to cigarette smoking [85]. In two studies where the men were followed for up to 12 months after smoking cessation, both studies reported a marked improvement in semen quality $[86,87]$. It is of great clinical interest to draw a parallel to other devastating effects of smoking. Smoking has a dose-dependent association with lung cancer and other epithelial malignancies [88, 89].

\section{Genital Operations}

Cryptorchidism is generally associated with impairment of germ cell maturation and subsequent infertility in adulthood [90]. In a recent study, out of 21 men who had cryptorchidism and subsequent orchidopexy, 6 men (28.6\%) who had had orchidopexy before 5 years of age had normal sperm parameters as adults, and 9 (42.9\%) had moderate-to-severe oligozoospermia [91]. The remaining $6(28.6 \%)$ had testicular atrophy, nonobstructive azoospermia, and low testosterone levels. In a review by 
Murphy et al. [92], in unilateral ectopic and emergent testes, the fertility outcome was good as long as the surgery was carried out in early childhood. However, men who underwent bilateral orchidopexyin in their childhood had an appreciably poorer prognosis for fertility compared to men who underwent a unilateral procedure. In another study, men who underwent unilateral orchidopexy in childhood before the age of 8 years had a better prognosis for fertility compared to those who had surgery later. Early diagnosis of cryptorchidism and orchidopexy in early childhood is advocated in order to sustain fertility in adulthood [93]. Secondly, it may be a sign of testicular dysgenesis syndrome [94]. Very few studies have evaluated fertility after herniorrhaphy [95]. In one study, more than half of all men who underwent inguinal repair as children had serum antisperm antibodies and low sperm counts, and both conditions were associated with decreased fertility [96]. In a series of 87 men with a history of herniorrhaphy, 49 (56.3\%) had testicular atrophy and low serum testosterone of less than $5 \mathrm{nmol} / \mathrm{l}, 52$ (59.8\%) had azoospermia, and another 31 (35.6\%) had severe oligozoospermia [91]. The introduction of minimally invasive techniques like laparoscopy in the last 15 years $[97,98]$ has improved the postoperative outcome. In a comparative study of laparoscopic versus open hernia repair by Bingener et al. [99], major morbidities in the open surgery group were 15 versus $7 \%$ in the laparoscopic group $(\mathrm{p}=0.01)$. Postoperative inpatient admission was more frequent after the open procedure than after the laparoscopic procedure ( 28 vs. $16 \%, \mathrm{p}<0.05$ ), thus encouraging a preference for laparoscopic hernia repair. Fertility potential was, however, not evaluated.

\section{Effects of Age on Sperm Parameters}

There are several studies suggesting that an increase in age is associated with a decline in semen parameters [100, 101]. Paulson et al. [102] identified an inverse association between age and total sperm count. In a study involving 97 healthy nonsmoking men aged $22-80$ years, Eskenazi et al. [103] showed that as the men aged, sperm parameters declined with a continuous reduction in sperm motility and semen volume. In a comparative study on the effects of advancing male age on multiple genomic defects in the human sperm DFI, chromatin integrity, gene mutations, and numerical chromosomal abnormalities, Wyrobek et al. [104] demonstrated a consistent decline in semen quality and increased sperm DNA damage, chromatin integrity, and gene mutations.

\section{Sperm Parameters and Male Health}

There are two lines of evidence that link sperm parameters to male health. Two Norwegian studies and a linkage study from England and Wales have shown that fertile couples live longer, especially if they have children, but it has not been determined whether this is due to biologic and/or social factors [105-107]. Epidemiological evaluation of the health disorders and sperm quality of 2,251 patients over a 16-year period showed that most health disorders have a deleterious effect on sperm parameters [46]. There is a rich body of literature on the effects of lifestyle habits such as substance abuse, cocaine or marijuana, and smoking on sperm quality [108-110]. Deficiencies in certain nutrients such as vitamins $\mathrm{C}$ and $\mathrm{E}$, folate, selenium, and zinc may lead to low sperm counts $[111,112]$.

\section{Sperm Parameters and the Longevity of Men}

A sperm concentration of $40 \mathrm{million} / \mathrm{ml}$ or more has been found to increase the probability of conception [6]. A higher mortality rate was found for infertile men without any specific comorbidity. This assertion has given credence to the assumption that disorders of spermatogenesis may be an indicator of exposure of the male organs to noxious agents within or outside the body environment. At the Third European Congress of Andrology and the 16th Congress of the German Society of Andrology, Groos et al. [13] demonstrated that men with normal sperm quality survived longer than men with poor sperm quality. The main criticism of this study was that it did not take the age of the participants and the duration of follow-up into consideration. These defects were corrected in a much larger Danish study from 1963 to 2001 [12]. All men who were referred to the Copenhagen Sperm Analysis Laboratory were included in the study. They were all linked to the Danish Cancer Registry, the National Register, and Statistics Denmark. Among 43,277 men without azoospermia referred for infertility problems, mortality decreased as the sperm concentration increased up to a threshold of $40 \mathrm{million} / \mathrm{ml}$. As the percentage of motile and morphologically normal spermatozoa and semen volume increased, mortality decreased in a dose-response manner due to a decrease in many diseases like infectious diseases (including tuberculosis), cancer, and cardiovascular, respiratory, digestive, and urogenital and endocrine diseases like diabetes mellitus. This was observed among men with and with-
$\mathrm{Omu}$ 
out children [12]. This study strongly demonstrated that semen quality may be a fundamental biomarker of overall male health.

\section{Mechanisms of Association between Sperm Parameters and Male Health}

\section{Primary Mechanisms}

There is increasing evidence that male reproductive disorders have become more prevalent during the last 50 years, with an increase in the incidence of testicular cancer and a decline in sperm counts $[113,114]$. Simultaneously, the incidence of congenital malformations of the male reproductive tract such as cryptorchidism and hypospadias has also increased [115]. Testicular cancer is associated with maldescent of the testis [116], reduced semen quality, and decreased fertility before cancer is diagnosed [117]. Against this background, Skakkebaek [118] proposed that these conditions are all symptoms of one underlying entity designated testicular dysgenesis syndrome, with a common origin in fetal life, in tacit support of the 'fetal origins hypothesis' proposed earlier by Barker [119]. According to this hypothesis, the fetal environment has been suggested to influence later health. Fetal malnutrition in utero and early life increases the risk of common adult diseases, such as cardiovascular disease and diabetes mellitus, and environmental factors, particularly nutrition, act in early life to potentiate the risks for adverse health outcomes in adult life. The mechanisms by which early life conditions are associated with male reproductive disorders and major late-life diseases are still not well understood. In a review, McMillen and Robinson [120] suggested critical windows during which perturbations of the intrauterine environment have major effects, and that epigenetic, structural, and functional adaptive responses result in a permanent programming of cardiovascular and metabolic disorders.

\section{Secondary Mechanisms}

Several mechanisms may account for the deleterious effects of obesity, diabetes mellitus, metabolic syndrome, smoking, genital injuries, and other health problems on sperm parameters. It has been suggested that insulin-dependent diabetes in men is associated with hypothalamopituitary derangement and impairment of semen quality [121] through low androgen levels. Sperm damage may be caused by oxidative stress, with adipose tissue acting as an endocrine organ, which produces adipokines, lowgrade inflammation, and proinflammatory cytokines, which results in insulin resistance and low testosterone [122-124]. In a recent review, Mammi et al. [125] showed that excessive adipose tissue is associated with impaired testosterone production. Spermatozoa were the first cell type reported to show a potential susceptibility to oxidative damage $[4,126,127]$. In a landmark paper published in 1943, MacLeod [4] confirmed a rapid loss of motility if spermatozoa were incubated in an oxygen-rich environment. Believing the loss of motility was due to an overproduction of oxidants arising from increased oxygen metabolism by sperm, he added the antioxidant catalase to the medium and restored motility, thereby successfully validating his hypothesis. The literature in andrology is replete with evidence of damage to sperm morphology and impairment of function by oxidative stress, with abundant production of free radicals from inflammation and abnormal sperm $[128,129]$, as shown in figure 2 . The white adipose tissue produces adipokines such as leptin, adiponectin, IL-6, and TNF- $\alpha$ with proinflammatory properties which lead to the development of oxidative stress [130-132]. Consequently, protein cross-linking and lipid peroxidation cause impairment of spermoocyte interactions due to loss of membrane fluidity. The $\mathrm{Y}$ chromosome is particularly susceptible to gene deletions because of the inability of the haploid genome to deploy recombination repair in retrieving lost genetic information. Sperm DNA damage and fragmentation may occur as a result of aberrant recombination, defective chromatin packaging, abortive apoptosis, and oxidative stress [133]. Oxidative stress and sperm DNA damage are common features of human spermatozoa, with purported links to poor rates of conception, impaired embryonic development, an increased incidence of miscarriage, and chronic morbidity in the offspring including childhood cancers [132]. This is particularly of clinical significance in uncontrolled diabetes mellitus with chronic hyperglycemia [134]. Hyperglycemia leads to production of advanced glycation end products (AGE), harbingers of proinflammatory cytokine production of TNF- $\alpha$ and IL-6, which cause insulin resistance. This leads to a vicious cycle of further hyperglycemia and resultant impairment of the hypothalamo-pituitary-testicular axis, culminating in decreased testosterone production. This results in endothelial dysfunction [134] and is simultaneously associated with oligozoospermia, asthenozoospermia, and sperm DNA apoptosis $[58,59]$. In another signaling pathway, hyperglycemia is associated with increased glycolysis and high pyruvate production with mitochondrial uncoupling and, consequently, production of sorbitol, AGE, and expression of AGE receptors (RAGE) [135], which 
Fig. 2. Effects of oxidative stress on sperm parameters. Oxidative stress is associated with impaired spermatogenesis, sperm morphological defects, sperm chromosome microdeletion, sperm DNA damage (fragmentation), reduced sperm capacitation, acrosome reaction, and fertilization. All abnormalities lead to infertility and miscarriage, congenital anomalies, and childhood cancer. OAT = Oligo-asthenoteratozoospermia; $\mathrm{ROS}=$ reactive oxygen species; ART = assisted reproductive technology.

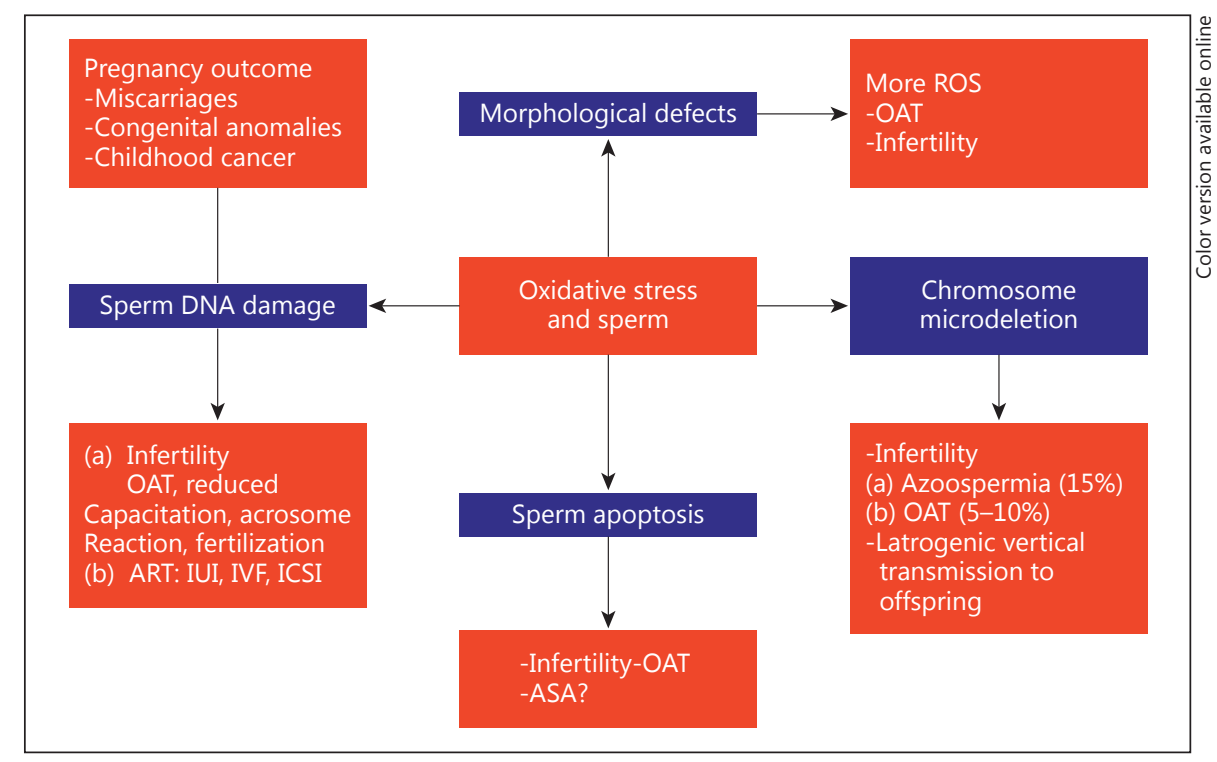

activate proinflammatory cytokine production and stress signaling [136].

Most (98\%) circulating testosterone is reversibly bound to albumin and sex-hormone-binding globulin (SHBG) [137]. SHBG is a protein manufactured in the liver that is responsible for the transportation of sex hormones testosterone, dihydrotestosterone, and estradiol. SHBG helps keep sex hormones in balance. Lower SHBG is more strongly associated with metabolic syndrome than is lower total testosterone in community-dwelling older men. SHBG may be the primary factor of these relationships, possibly reflecting its association with insulin sensitivity [138, 139]. Reduced circulating testosterone and SHBG are implicated as risk factors for metabolic syndrome [138] and may therefore be strongly associated with reduced sperm quality. Epidemiological observations suggest that low androgens, especially testosterone, and SHBG, are associated with high BMI [139], nonobese diabetes mellitus [59], hypertension [140], and metabolic syndrome $[61,141,142]$.

As shown in figure 3, low testosterone levels in men may be associated with increased cardiovascular risk $[143,144]$. A European prospective study among men aged 40-79 years showed that endogenous testosterone concentrations were inversely associated with all-cause mortality and cardiovascular mortality [145], in confirmation of an earlier report [116]. Several mechanisms have been implicated in the association between low testosterone levels and cardiovascular disease. Low testosterone has been linked to elevated triglyceride and low high-density lipoprotein levels, central or visceral obesity, glucose intolerance, and diabetes mellitus [146, 147]. Reduced testosterone is associated with increased levels of several cytokines and growth factors such as TNF- $\alpha$, IL-6, IL-1 $\beta$, and CRP [147]. In a report by van Guilder et al. [148], an increased level of oxidative and inflammatory stress played an important role in the initiation and progression of atherosclerotic vascular disease. Furthermore, elevated proinflammatory cytokines, including TNF- $\alpha$, IL-6, and IL-18, as well as CRP, are markers of systemic inflammation and strong determinants of future atherosclerotic events. In summary, while oxidative stress and low grade inflammation are associated with poor sperm parameters, they are also potential mechanisms underlying the increased cardiovascular and renal risks in obese adults with metabolic syndrome $[60,62,63]$.

\section{Limitations of Utility of Association between Sperm Parameters and Male Health Status}

A better understanding of the association between sperm parameters and general health could lead to possible pharmacological development and interventions that could delay, alter, or prevent the progression and development of medical complications and effects on sperm parameters. However, there is a need to exercise caution on two main fronts. While drugs like gentamycin, used for infections, may improve the general health of the patient, they may have directly adverse effects on spermatogenesis DOI: $10.1159 / 000354208$
$\mathrm{Omu}$ 


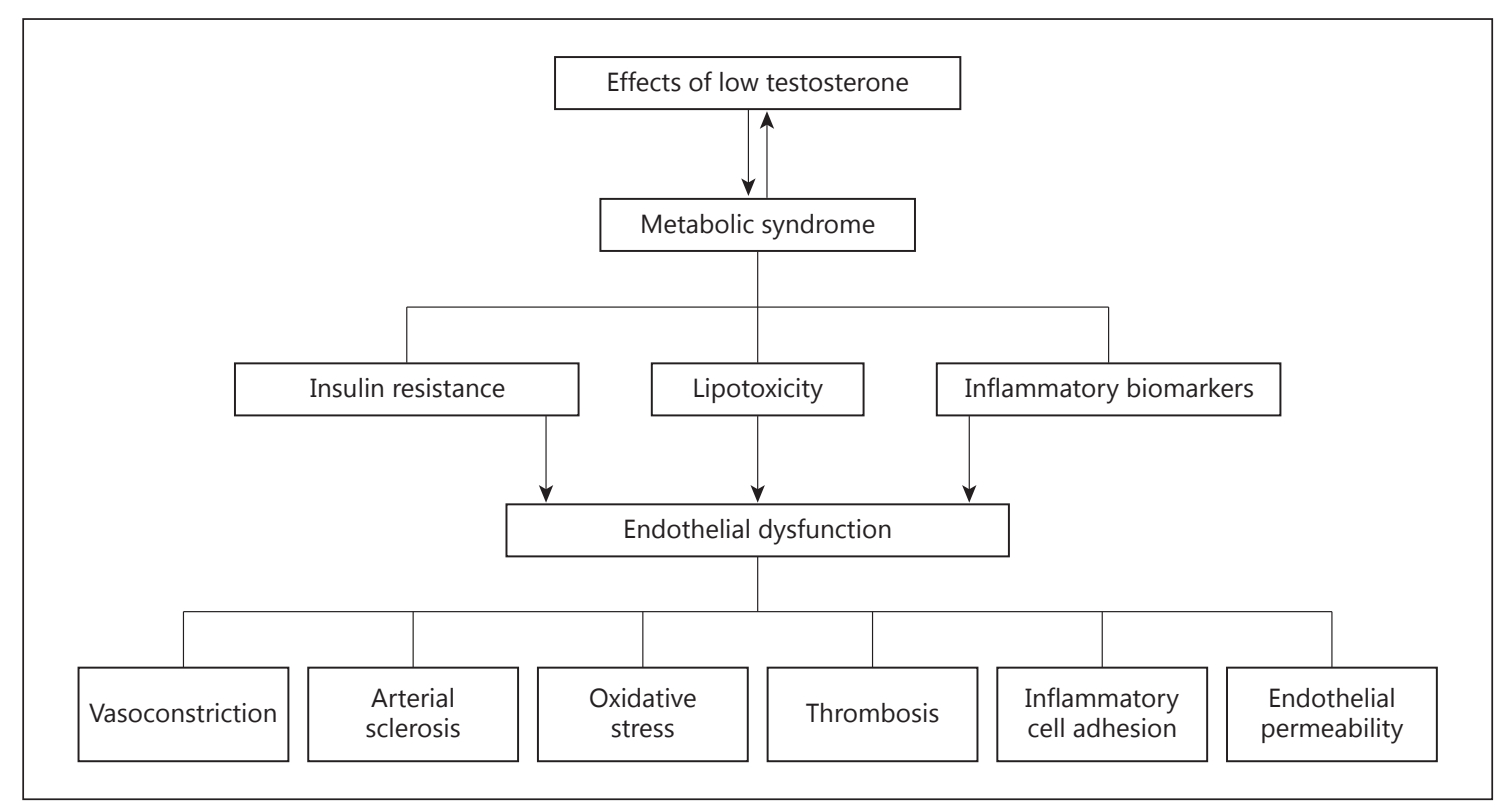

Fig. 3. Effects of low testosterone on spermatogenesis and male health. Testosterone is essential for spermatogenesis. Low testosterone leads to reduced sperm counts and increased sperm morphological defects. There is a strong bilateral association between low testosterone and metabolic syndrome, insulin resistance, and diabetes mellitus. This may lead to production of biomarkers of inflammation and oxidative stress. Ultimately, this may cause endothelial dysfunction, which may give rise to atherosclerosis and coronary heart disease.

and sperm parameters [148]. Another difficulty in advocating sperm parameters as biomarkers of individual male health is the variation in semen quality from the effects of biological, environmental, and seasonal changes on spermatogenesis $[149,150]$, and the use of different parameters of assessment of sperm quality among laboratories $[39,151]$. Lifestyle changes in the form of weight reduction, exercise, cessation of smoking, and a balanced diet may differentially improve sperm parameters and general health $[52,138]$. In a recent study, combinations of adverse lifestyle factors had a detrimental impact on sperm in terms of motility and sperm count. This negative impact was shown to be compensated by a higher ejaculation frequency and a shorter period of sexual abstinence [152]. The compensation is most likely due to a shorter storage time in the male gonads, thus reducing the duration of sperms' exposure to reactive oxygen species [153].

\section{Conclusion}

There are a number of difficulties in using semen parameters for screening to determine male health status. The physiological variation of spermatogenesis and the significant impact of individual lifestyle choices such as

Sperm Parameters Are an Index of Good Health and Longevity exercise, diet, and health awareness are important variables. There is compelling evidence of an association between medical disorders, social habits, and sperm parameters. Through various mechanisms, sperm parameters are affected early in the pathogenesis of medical disorders. However, the use of sperm parameters for monitoring male health requires further evaluation for the role of age, environment, and congenital abnormalities of the genital tract. With advances in proteomics, personalized therapy for male infertility and medical disorders will be achievable.

\section{Acknowledgement}

I am grateful to the Research Sector, Kuwait University, for research grants MO031, 033, and 254, which made this review possible. The technicians in my department and my medical colleagues and nurses at the Maternity Hospital worked with me with absolute dedication and professionalism. I acknowledge with gratitude the loyalty and contribution of all the patients from my clinic.

\section{Disclosure Statement}

The author declares that no conflicts of interest exist. 


\section{References}

1 Dobell C (ed): Antony van Leeuwenhoek and $>20$ Biomarkers Definitions Working Group: BioHis 'Little Animals'. New York, Dover, 1960, pp 388-422.

2 Frank N, Egerton A: History of the ecological sciences, part 19: Leeuwenhoek's microscopic natural history. Bull Ecol Soc Am 2006;87: 47-58.

3 Pinto-Correia C: The Ovary of Eve: Egg and Sperm. Chicago, University of Chicago Press, 1993, pp 74-76.

4 MacLeod J: The role of oxygen in the metabolism and motility of human spermatozoa. Am J Physiol 1943;138:512-518.

5 World Health Organization: WHO Laboratory Manual for the Examination and Processing of Human Semen, ed 5. Geneva, WHO, 2010.

6 Bonde JP, Emst E, Jensen TK, et al: Relation between semen quality and fertility: a population based study of 430 first pregnancy planners. Lancet 1998;352:1172-1177.

7 Zhao GQ, Garbers DL: Male germ cell specification and differentiation. Dev Cell 2002;2: 537-547.

8 Turner TT: De Graaf's thread: the human epididymis. J Androl 2008;29:237-250.

$>9$ Tiepolo L, Zuffardi O: Localisation of factors controlling spermatogenesis in the non-fluorescent portion of the human chromosome $\mathrm{Y}$ long arm. Hum Genet 1976;34:119-124.

-10 Dada R, Gupta NP, Kucheria K: Yq microdeletions - azoospermia factor candidate genes and spermatogenic arrest. J Biomol Tech 2004; 15:176-183.

11 Zirkin BR: Spermatogenesis: its regulation by testosterone and FSH. Semin Cell Dev Biol 1998;9:417-421.

$>12$ Jensen TK, Jacobsen R, Christensen K, et al: Good semen quality and life expectancy: a cohort study of 43,277 men. Am J Epidemiol 2009; 170:559-565.

13 Groos S, Krause W, Mueller U: Lifetime mortality of men with normal and subnormal sperm counts in young adulthood. Andrologia 2004;36:169-170.

14 World Health Organization: Preamble to the Constitution of the WHO as Adopted by the International Health Conference, New York, 1946. Geneva, WHO, 1948.

15 World Health Organization: Constitution of the World Health Organization - Basic Documents, ed 45 (supplement 2006). Geneva, WHO, 2006.

16 McEwen BS: Protective and damaging effects of stress mediators: central role of the brain. Dialogues Clin Neurosci 2006;8:367-381.

17 World Health Organization: Deaths by Cause, Sex and Mortality Stratum in WHO Estimates for 2002 - The World Health Report 2004. Geneva, WHO, 2004, pp 20-21.

-18 Siddiquil A, Jaleel A, Al'Kadri HMF, et al: Biomarkers of oxidative stress in women with pre-eclampsia. Biomark Med 2013;7:229234.

19 Neagu M, Albulescu R, Tanase C: Research highlights: highlights from the latest articles in biomarkers in medicine. Biomark Med 2013;7:201-204. markers and surrogate endpoints: preferred definitions and conceptual framework. Clin Pharmacol Ther 2001;69:89-95.

21 Vaidya VS, Ozer JS, Dieterle F, et al: Kidney injury molecule-1 outperforms traditional biomarkers of kidney injury in preclinical biomarker qualification studies. Nat Biotechnol 2010;28:478-485.

22 Al-Azemi MK, Omu AE, Fatinikun T, et al: Factors contributing to gender differences in serum retinol and alpha-tocopherol in infer tile couples. Reprod Biomed Online 2009;19: 583-590.

23 Ozer JS, Dieterle F, Troth S, et al: A panel of urinary biomarkers to monitor reversibility of renal injury and a serum marker with improved potential to assess renal function. Nat Biotechnol 2010;28:486-494.

24 Meigs JB: Multiple biomarker predictions of type 2 diabetes. Diabetes Care 2009;32:13461348.

25 Duffy MJ: Tumor markers in clinical practice: a review focusing on common solid cancer. Med Princ Pract 2013;22:4-11.

26 Raman JD, Nobert CF, Goldstein M: Increased incidence of testicular cancer in men presenting with infertility and abnormal semen analysis. Urol 2005;174:1819-1822.

$>27$ Williams DH, Karpman E, Sander JC, et al: Pretreatment semen parameters in men with cancer. J Urol 2009;11:736-740.

28 Meirow D, Schenker JG: Cancer and male infertility. Hum Reprod 1995;10:2017-2229.

29 Brewis IA, Gadella BM: Sperm surface proteomics: from protein lists to biological function. Mol Hum Reprod 2010;16:68-79.

30 Irvine DS: Epidemiology and aetiology of male infertility. Hum Reprod 1998;13:33-44.

31 Lamb DJ: Semen analysis in 21st century medicine: the need for sperm function testing. Asian J Androl 2010;12:64-70.

32 Kashou AH, Benjamin DJ, Agarwal A, et al: The advent of sperm proteomics has arrived. Open Reprod Sci J 2011;3:92-97.

33 Tomar AK, Sooch BS, Singh S, et al: Differential proteomics of human seminal plasma: a potential target for searching male infertility marker proteins. Proteomics Clin Appl 2012; 6:147-151.

34 Siva AB, Kameshwari DB, Singh V, et al: Proteomics-based study on asthenozoospermia: differential expression of proteasome alpha complex. Mol Hum Reprod 2010;16:452-462.

35 Lazaros L, Kaponis A, Vartholomatos G, et al: Using semen flow cytometry to evaluate association of ploidy status and chromatin condensation of spermatozoa with conventional semen parameters: clinical application in intrauterine insemination. Fertil Steril 2011;95: 110-115.

36 Evenson DP, Jost LK, Marshall D, et al: Utility of the sperm chromatin structure assay as a diagnostic and prognostic tool in the human fertility clinic. Hum Reprod 1999;14:1039-1049.

37 Lewis SEM, Simon L: Clinical implications of sperm DNA damage. Hum Fertil (Camb) 2010;13:201-207.
38 Carlsen E, Giwercman A, Keiding N, et al: Evidence for decreasing quality of semen during past 50 years. BMJ 1992;305:609-613.

39 Auger J, Kunstmann JM, Czyglik F, et al: Decline in semen quality among fertile men in Paris during the past 20 years. N Engl J Med 1995;332:281-285.

40 Olsen GW, Bodner KM, Ramlow JM, et al: Have sperm counts been reduced 50 percent in 50 years? A statistical model revisited. Fertil Steril 1995;63:887-893.

41 Main KM, Skakkebaek NE, Toppari J: Cryptorchidism as part of the testicular dysgenesis syndrome: the environmental connection. Endocr Dev 2009; 14:167-173.

42 Burns WR, Sabanegh E, Dada R, et al: Is male infertility a forerunner to cancer? Int Braz J Urol 2010;36:527-536.

43 Skakkebæk NE, Rajpert-De Meyts E, Main KM: Testicular dysgenesis syndrome: an increasingly common developmental disorder with environmental aspects. Hum Reprod 2001;16:972-978.

44 Sharpe RM, Franks S: Environment, lifestyle and infertility: an inter-generational issue. Nat Cell Biol 2002;4:S33-S34.

45 Sharpe RM: Hormones and testis development and the possible adverse effect of environmental chemicals. Toxicol Lett 2001;120: 221-232.

46 Omu AE, Al-Azemi MK, Al-Jassar W, et al: Effects of medical disorders and social habits on sperm parameters (No 114). HSC Poster Conference, Kuwait, 2013.

47 Sallmen M, Sandler DP, Hoppin JA, et al: Reduced fertility among overweight and obese men. Epidemiology 2006;17:520-523.

48 Ramlau-Hansen CH, Thulstrup AM, Nohr EA, et al: Subfecundity in overweight and obese couples. Hum Reprod 2007;22:16341637.

49 Aggerholm AS, Thulstrup AM, Toft G, et al: Is overweight a risk factor for reduced semen quality and altered serum sex hormone profile. Fertil Steril 2008;90; 619-626.

50 Nguyen RH, Wilcox AJ, Skjaerven R, et al: Men's body mass index and infertility. Hum Reprod 2007;22:2488-2493.

51 Magnusdottir EV, Thorsteindottir T, Thorsteindottir $\mathrm{S}$, et al: Persistent organochlorines, sedentary occupation, obesity and human male subfertility. Hum Reprod 2005;20:208215.

52 Qin DD, Yuan W, Zhou WJ, et al: Do reproductive hormones explain the association between body mass index and semen quality? Asian J Androl 2007;9:827-834.

53 Fariello RM, Pariz JR, Spaine DM, et al: Association between obesity and alteration of sperm DNA integrity and mitochondrial activity. BJU Int 2012;110:863-868.

54 Chavarro JE, Toth TL, Wright DL, et al: Body mass index in relation to semen quality, sperm DNA integrity, and serum reproductive hormone levels among men attending an infertility clinic. Fertil Steril 2010;93:22222231. 
-55 Hammoud AO, Gibson M, Peterson CM, et al: Impact of male obesity on infertility: a critical review of the current literature. Fertil Steril 2008;90:897-904.

56 Chung WS, Sohn JH, Park YY: Is obesity an underlying factor in erectile dysfunction? Eur Urol 1999;36:68-70.

57 Kapoor D, Clarke S, Channer KS, et al: Erectile dysfunction is associated with low bioactive testosterone levels and visceral adiposity in men with type 2 diabetes. Int J Androl 2007; 30:500-507.

58 Kort HI, Massey JB, Elsner CW, et al: Impact of body mass index values on sperm. quantity and quality. J Androl 2006;27:450-452.

59 Bakos HW, Mitchell M, Setchell BP, et al: The effect of paternal diet-induced obesity on sperm function and fertilization in a mouse model. Int J Androl 2011;34:402-410.

60 Omu AE, Kehinde E, Al-Azemi MK, et al: The effects of diabetes mellitus on the ontogeny of human sperm: the role for antioxidants. Androl Update 2007;1:157-164.

-61 Agbaje M, Rogers DA, McVicar CM, et al: Insulin dependent diabetes mellitus: implications for male reproductive function. Hum Reprod 2007;22:1871-1877.

62 Gorbachinsky I, Akpina H, Assimos DG: Metabolic syndrome and urologic diseases. Rev Urol 2010;12:e157-e180.

-63 Laaksonen DE, Niskanen L, Punnonen K, et al: Sex hormones, inflammation and the metabolic syndrome: a population-based study. Eur J Endocrinol 2003;149:601-608.

64 Malik S, Wong ND, Franklin S, et al: Cardiovascular disease in US patients with metabolic syndrome, diabetes, and elevated C-reactive protein. Diabetes Care 2005:28:690-693.

65 Faloia E, Michetti G, De Robertis M, et al: Inflammation as a link between obesity and metabolic syndrome. J Nutr Metab 2012; 2012:476380.

66 Haffner SM, Mykkanen L, Valdez RA, et al: Relationship of sex hormones to lipids and lipoproteins in nondiabetic men. J Clin Endocrinol Metab 1993;77:1610-1615.

- 67 Robeva R, Kirilov G, Tomova A, et al: Low testosterone levels and unimpaired melatonin secretion in young males with metabolic syndrome. Andrologia 2006;38:216-220.

-68 Kasturi SS, Tannir J, Brannigan RE: The metabolic syndrome and male infertility. J Androl 2008;29:251-259.

-69 Taube A, Schlich R, Sell H, et al: Inflammation and metabolic dysfunction: links to cardiovascular diseases. Am J Physiol Heart Circ Physiol 2012;302:148-165.

-70 Shin MJ, Lee KH, Chung JH, et al: Circulating IL-8 levels in heart failure patients with and without metabolic syndrome. Clin Chim Acta 2009;405:139-142.

71 Benoff S, Cooper GW, Hurley I, et al: The effect of calcium ion channel blockers on sperm fertilization potential. Fertil Steril 1994;62: 606-617.

72 Muciaccia B, Pensini S, Culasso F, et al: Higher clusterin immunolabeling and sperm DNA damage levels in hypertensive men compared with controls. Hum Reprod 2012;27:22672276.
Kirkman-Brown J, Barratt CLR, Publicover SJ: Nifedipine reveals the existence of two discrete components of the progesterone-induced $[\mathrm{Ca}(2+)] \mathrm{i}$ transient in human spermatozoa. Dev Biol 2003;259:71-82.

74 Omu AE, Al-Othman S, Mohammad AS: Antibiotics therapy for seminal infection: effect on antioxidant activity and T-helper cytokines. J Reprod Med 1998;43:857-864.

75 Mazzoli S, Cai T, Addonisio P, et al: Chlamydia trachomatis infection is related to poor semen quality in young prostatitis patients. Eur Urol 2010;57:708-714.

76 Al-Sweih NA, Al Fadli AH, Omu AE, et al: Prevalence of Chlamydia trachomatis, Mycoplasma hominis, Mycoplasma genitalium and Ureaplasma urealyticum infections and seminal quality in infertile and fertile men in $\mathrm{Ku}$ wait. J Androl 2012;13:1323-1329.

77 Al-Sweih NA, Fadhi AH, Omu AE, et al: Semen quality in males with latent genital infection. J Androl 2012;33:1331.

-78 Okoror LE, Agbonlahor DE: High prevalence of Chlamydia trachomatis in the sperm of males with low sperm count in Nigeria. J Med Microb Diagn 2012;1:108-113.

79 Lorusso F, Palmisano M, Chironna M, et al: Impact of chronic viral diseases on semen parameters. Andrologia 2010;42:121-126.

80 Marinelli D, Gaspari L, Fedota E, et al: Mini review of studies on the effect of smoking and drinking habits on semen parameters. Int J Hyg Environ Health 2004;207:185-192.

81 Künzle R, Mueller MD, Hänggi W, et al: Semen quality of male smokers and nonsmokers in infertile couples. Fertil Steril 2003;79:287291.

82 Holzki G, Gall H, Hermann J: Cigarette smoking and sperm quality. Andrologia 1991;23: 141-144.

83 Al-Bader A, Omu AE, Dashti H: Chronic cadmium toxicity to sperm of heavy cigarette smokers: immunomodulation by zinc. Arch Androl 1999;43:135-140.

84 Omu AE, Dashti H, Mohammed AT, et al: Cigarette smoking causes impairment of spermatozoal quality: andrological and biochemical evaluation. Med Princ Pract 1998;7: 47-53.

85 Fawzy IA, Kamal NN, Abdulla AM: Reproductive toxicity of tobacco shisha smoking on semen parameters and hormones levels among adult Egyptian men. Res J Environ Toxicol 2011;5:282-292.

86 Sofikitis N, Miyagawa I, Dimitriadis D, et al: Effects of smoking on testicular function, semen quality and sperm fertilizing capacity. J Urol 1995;154:1030-1034.

87 Prentki-Santos E, López-Costa S, Chenlo P, et al: Impact of spontaneous smoking cessation on sperm quality: case report. Andrologia 2011;43:431-435.

88 Kjærbye-Thygesen A, Frederiksen K, Høgdall EV, et al: Smoking and overweight: negative prognostic factors in stage III epithelial ovarian cancer. Cancer Epidemiol Biom Prev 2006;15:798-803.
89 Nagathihalli NS, Massion PP, Gonzalez AL et al: Smoking induces epithelial-to-mesenchymal transition in non-small cell lung cancer through HDAC- mediated downregulation of E-cadherin. Mol Cancer Ther 2012;11:2362-2372.

90 Chung E, Brock GB: Cryptorchidism and its impact on male fertility: a state of art review of current literature. Can Urol Assoc J 2011; 5:210-214.

91 Omu AE, Al-Azemi MK, Al-Jassar W, et al: Genital operations and male infertility: is inguinal hernia a component of testicular dysgenesis syndrome? (No 119). HSC Poster Conference, Kuwait, 2013.

92 Murphy F, Paran TS, Puri P: Orchidopexy and its impact on fertility. Pediatr Surg Int 2007;23:625-632.

-93 Trsinar B, Muravec UR: Fertility potential after unilateral and bilateral orchidopexy for cryptorchidism. World J Urol 2009;27:513519.

-94 Toppari J, Virtanen HE, Main KM, et al: Cryptorchidism and hypospadias as a sign of testicular dysgenesis syndrome (TDS): environmental connection. Birth Defects Res A Clin Mol Teratol 2010;88:910-919.

$\$ 95$ Bendavid R: The unified theory of hernia formation. Hernia 2004;8:171-176.

-96 Bax T, Sheppard BC, Crass RA: Surgical options in the management of groin hernias. Am Fam Physician 1999;59:143-156.

97 Ridgway PF, Shah J, Darzi AW: Male genital tract injuries after contemporary inguinal hernia repair. BJU Int 2002;90:272-276.

-98 Payne JH Jr, Grininger LM, Izawa MT, et al: Laparoscopic or open inguinal herniorrhaphy? A randomized prospective trial. Arch Surg 1994;129:973-979.

-99 Bingener J, Buck L, Richards M, et al: Longterm outcomes in laparoscopic vs. open ventral hernia repair. Arch Surg 2007;142:562567.

100 Centola GM, Eberly S: Seasonal variations and age-related changes in human sperm count, motility, motion parameters, morphology, and white blood cell concentration. Fertil Steril 1999;72:803-808.

101 Kidd SA, Eskenazi B, Wyrobek AJ: Effects of male age on semen quality and fertility: a review of the literature. Fertil Steril 2001;75: 237-248.

102 Paulson RJ, Milligan RC, Sokol RZ: The lack of influence of age on male fertility. Am J Obstet Gynecol 2001;184:818-822.

103 Eskenazi B, Wyrobek AJ, Sloter E, et al: The association of age and semen quality in healthy men. Hum Reprod 2003;18:447454.

104 Wyrobek AJ, Eskenazi B, Young S, et al: Advancing age has differential effect on DNA damage, chromatin integrity, gene mutations, and aneuploidies in sperm. Proc Natl Acad Sci USA 2006;103:9601-9606.

105 Ringbäck Weitoft G, Burström B, Rosén M: Premature mortality among lone fathers and childless men. Soc Sci Med 2004;59:1449_ 1459. 
106 Grundy E, Tomassini C: Fertility history and health in later life: a record linkage study in England and Wales. Soc Sci Med 2005;61: 217-228.

107 Grundy E, Kravdal Ø: Reproductive history and mortality in late middle age among Norwegian men and women. Am J Epidemiol 2008;167:271-279.

108 Close CE, Roberts PL, Berger RE: Cigarettes, alcohol and marijuana are related to pyospermia in infertile men. J Urol 1990;144: 900-903.

109 Bracken MB, Eskenazi B, Sachse K, et al: Association of cocaine use with sperm Fertil Steril 1990;53:315-322.

$\checkmark 110$ Hurd WW, Kelly MS, Ohl DA, et al: The effect of cocaine on sperm motility characteristics and bovine cervical mucus penetration. Fertil Steril 1992;57:178-182.

$\checkmark 11$ Omu AE, Dashti H, Al-Othman S: Treatment of asthenozoospermia with zinc sulphate: andrological, immunological and obstetric outcome. Eur J Obstet Gynecol 1998; 79:179-184.

$\$ 112$ Rolf C, Cooper TG, Yeung CH, et al: Antioxidant treatment of patients with asthenozoospermia or moderate oligoasthenozoospermia with high-dose vitamin $\mathrm{C}$ and vitamin E: a randomized, placebo-controlled, double-blind study. Hum Reprod 1999;14: 1028-1033.

113 Carlsen E, Giwercman AJ, Keiding N, et al: Declining semen quality and increasing incidence of testicular cancer: is there a common cause? Environ Health Perspect 1995; 103:137-139.

114 Baker JA, Buck GM, Vena JE, et al: Fertility patterns prior to testicular cancer diagnosis. Cancer Causes Control 2005;16:295-299.

-115 Toppari J, Kaleva M, Virtanen HE: Trends in the incidence of cryptorchidism and hypospadias, and methodological limitations of registry-based data. Hum Reprod Update 2001;7:282-286.

116 Giwercman A, Grindsted J, Hansen B, et al: Testicular cancer risk in boys with maldescended testis: a cohort study. J Urol 1987; 138:1214-1216.

117 Møller H, Skakkebaek NE: Risk of testicular cancer in subfertile men: case-control study. BMJ 1999;318:559-562.

-118 Skakkebaek NE: Testicular dysgenesis syndrome: new epidemiological evidence. Int J Androl 2004;27:189-191.

119 Barker DJ: The developmental origins of adult disease. J Am Coll Nutr 2004;23:588S$595 S$.

120 McMillen IC, Robinson JS: Developmental origins of the metabolic syndrome: prediction, plasticity, and programming. Physiol Rev 2005;85:571-633.

-121 Baccetti B, La Marca A, Piomboni P, et al: Insulin-dependent diabetes in men is associated with hypothalamo-pituitary derangement and with impairment in semen quality. Hum Reprod 2002;17:2673-2677.

122 Shores MM, Matsumoto AM, Sloan KL, et al: Low serum testosterone and mortality in male veterans. Arch Intern Med 2006;166: $1660-1665$.
123 Kershaw EE, Flier JS: Adipose tissue as an endocrine organ. J Clin Endocrinol Metab 2004;99:2548-2556.

124 Du Plessis SS, Cabler S, McAlister DA, et al: The effect of obesity on sperm disorders and male infertility. Nat Rev Urol 2010;7:153-161.

125 Mammi C, Calanchini M, Antelmi A, et al: Androgens and adipose tissue in males: a complex and reciprocal interplay. Int J Endocrinol 2012;2012:789653.

126 Gharagozloo P, Aitken RJ: The role of sperm oxidative stress in male infertility and the significance of oral antioxidant therapy. Hum Reprod 2011;26:1628-1640.

127 Lenzi A, Picardo M, Gandini L, et al: Lipids of the sperm plasma membrane: from polyunsaturated fatty acids considered as markers of sperm function to possible scavenger therapy. Hum Reprod Update 1996;2:246256.

128 Tremellen C: Oxidative stress and male infertility. Hum Reprod Update 2008;14:243258.

129 Jensen MD: Adipose tissue as an endocrine organ: implication of its distribution on free fatty acid metabolism. Eur Heart J Suppl 2006; 8: B13-B19.

130 Rabe K, Lehrke M, Parhofer KG, et al: Adipokines and insulin resistance. Mol Med 2008;14:741-751.

-131 Aitken RJ, Baker MA, Sawyer D: Oxidative stress in the male germ line and its role in the aetiology of male infertility. Reprod Biomed Online 2003;7:65-70.

132 Aitken RJ, Krausz C: Oxidative stress, DNA damage and the $\mathrm{Y}$ chromosome. Reproduction 2001;122:497-506.

133 Aitken RJ, De Iuliis GN, McLachlan RI: Biological and clinical significance of DNA damage in the male germ line. Int J Androl 2009;32:46-56.

134 Brownlee M: Biochemistry and molecular cell biology of diabetic complications. $\mathrm{Na}$ ture 2001;414:813 -820.

135 Yao D, Brownlee M: Hyperglycemia-induced reactive oxygen species increase expression of the receptor for advanced glycation end products (RAGE) and RAGE ligands. Diabetes 2010;59:249-255.

136 Evans JL, Goldfine ID, Maddux BA, et al: Are oxidative stress-activated signaling pathways mediators of insulin resistance and $\beta$-cell dysfunction? Diabetes 2003;52:1-8.

137 Brand JS, van der Tweel I, Grobbee DE, et al: Testosterone, sex hormone-binding globulin and the metabolic syndrome: a systematic review and meta-analysis of observational studies. Int J Epidemiol 2011;40:189207.

138 Chubb SA, Hyde Z, Almeida OP, et al: Lower sex hormone-binding globulin is more strongly associated with metabolic syndrome than lower total testosterone in older men: the Health in Men Study. Eur J Endocrinol 2008; 158:785-792.

-139 Osuna JA, Gomex-Perez R, Arata-Bellabarba G, et al: Relationship between BMI, total testosterone, sex-hormone binding globulin, leptin, insulin and insulin resistance in obese men. Arch Androl 2005;52:355-361.
140 Svartberg J, Muhlen D, Schirmer H, et al: Association of endogenous testosterone with blood pressure and left ventricular mass the Tromso study. Reprod J Endocrinol 2004;150:68-71.

141 Dallmeier D, Larsen M, Vasan R, et al: Metabolic syndrome and inflammatory biomarkers: a community-based cross-sectional study at the Framingham Heart Study. Diabetol Metab Syndr 2012;4:28.

142 Li C, Ford ES, Li B, et al: Association of testosterone and sex hormone-binding globulin with metabolic syndrome and insulin resistance in men. Diabetes Care 2010;33: 1618-1624.

143 Ma RCW, Tong CY: Testosterone levels and cardiovascular disease. Heart 2010;96:17871788.

144 Khaw K, Dowsett M, Folkerd E, et al: Endogenous testosterone and mortality due to all causes, cardiovascular disease and cancer in men. Circulation 2007;116:2694-2701.

145 Kapoor D, Malkin CJ, Channer KS, et al: Androgens, insulin resistance and vascular disease in men. Clin Endocrinol 2005;63:239250.

146 Tong PC, Ho CS, Yeung VT, et al: Association of testosterone, insulin-like growth factor-I, and C-reactive protein with metabolic syndrome in Chinese middle-aged men with a family history of type 2 diabetes. J Clin Endocrinol Metab 2005;90:6418-6423.

147 Malkin CJ, Pugh PJ, Jones RD, et al: The effect of testosterone replacement on endogenous inflammatory cytokines and lipid profiles in hypogonadal men. J Clin Endocrinol Metab 2004;89:3313-3318.

148 Van Guilder GP, Hoetzer GL, Greiner JJ, et al: Influence of metabolic syndrome on biomarkers of oxidative stress and inflammation in obese adults. Obesity 2006;14:21272131.

149 Khaki A, Novin MG, Khaki AA, et al: Comparative study of the effects of gentamicin neomycin, streptomycin and ofloxacin antibiotics on sperm parameters and testis apoptosis in rats. Pak J Biol Sci 2008;11:16831689.

150 Celino FT, Yamaguchi S, Miura C, et al: Tolerance of spermatogonia to oxidative stress is due to high levels of $\mathrm{Zn}$ and $\mathrm{Cu} / \mathrm{Zn}$ superoxide dismutase. PLoS One 2011;6:e16938.

151 Alvarez C, Castilla JA, Martínez L, et al: Biological variation of seminal parameters in healthy subjects. Hum Reprod 2003;18: 2082-2088.

152 Jørgensen N, Andersen A-G, Eustache F, et al: Regional differences in semen quality in Europe. Hum Reprod 2001;16:1012-1019.

153 Anderson K, Nisenblat V, Norman R: Lifestyle factors in people seeking infertility treatment: a review. Aust NZ J Obstet Gynaecol 2010;50:8-20.

154 Wogatzky J, Wirleitner B, Stecher A, et al: The combination matters - distinct impact of lifestyle factors on sperm quality: a study on semen analysis of 1,683 patients according to MSOME criteria. Reprod Biol Endocrinol 2012;10:115. 